\title{
LINEAMENTOS JUSFILOSÓFICOS DA JURISDIÇÃO: DO POSITIVISMO AO PÓS-POSITIVISMO PROCEDIMENTAL
}

\author{
Carlos André Maciel Pinheiro Pereira134 \\ Andressa Solon Borges135 \\ Nathânia de Medeiros Oliveira136
}

Recebido em: 29/04/2019

Aprovado em: 18/09/2019

\begin{abstract}
RESUMO
Este artigo pretende estudar um modelo de decisão judicial apto a corresponder aos interesses da cidadania pluralista. Faz uso do método dialético em um primeiro momento e dedutivo no subsequente. É uma pesquisa qualitativa e normativa. Utiliza fontes de pesquisa doutrinária com ênfase em autores da filosofia do direito e teoria do direito constitucional. Entende que as teorias do positivismo de Hart, do pós-positivismo de Dworkin e Alexy e do pragmatismo jurídico de Posner são insuficientes para justificar a legitimidade das decisões. Encontra em Habermas um modelo procedimental de jurisdição que permite o diálogo democrático e cooperativo entre os atores processuais. Em seguida, investiga a aplicação da teoria habermasiana na jurisdição ordinária com ênfase no processo penal e na jurisdição constitucional com suporte em Ricardo Tinoco de Góes. Por fim, sugere que a proposta de Habermas seja utilizada para futuras investigações sobre a aplicabilidade na legislação brasileira.
\end{abstract}

Palavras-chave: Legitimidade da decisão judicial. Democracia deliberativa. Pós-positivismo procedimental.

\section{INTRODUÇÃO}

\footnotetext{
${ }^{134}$ Bacharel em Direito pelo Centro Universitário do Rio Grande do Norte (UNI-RN). Especialista em Direito Tributário pelo Instituto Brasileiro de Estudos Tributários (IBET). Mestre em Direito Constitucional pela Universidade Federal do Rio Grande do Norte (UFRN). Professor DNS I da Universidade Potiguar (UnP). Advogado.

${ }^{135}$ Bacharela em Direito pelo Centro Universitário do Rio Grande do Norte (UNI-RN). Especialista em Direito Civil pela Faculdades Integradas de Jacarepaguá (FIJ). Especialista em Direito Público pela Instituto de Ensino Superior de Fortaleza (IESF). Mestra em Direito Constitucional pela Universidade Federal do Rio Grande do Norte (UFRN). Técnica Judiciária do Tribunal de Justiça do Rio Grande do Norte (TJRN).

${ }^{136}$ Bacharela em Direito pela Universidade Federal do Rio Grande do Norte (UFRN). Bacharela em Filosofia pela Universidade Federal do Rio Grande do Norte (UFRN). Mestra em Direito Constitucional pela Universidade Federal do Rio Grande do Norte (UFRN). Advogada.
} 
O presente artigo terá como objetivo traçar um modelo adequado de jurisdição que esteja antenada aos pressupostos de uma democracia radical. A problemática está situada em encontrar qual o melhor método de decisão a ser aplicado em face das sociedades plurais contemporâneas. Fará uso do método dialético, confrontando as posições de cada um dos autores estudados para no final utilizar do método dedutivo, contextualizando o conhecimento construído.

Será uma pesquisa qualitativa e normativa, pois pretenderá trazer um modelo ideal a servir de norte para a atividade judicante brasileira. Ainda, se utilizará de pesquisa bibliográfica baseada em juristas e filósofos que tratam da temática em questão e, por não ter viés explicativo, não fará uso de análise documental ou jurisprudencial.

Iniciará falando da teoria de H.L.A. Hart para falar das regras de conhecimento e como as lacunas são preenchidas pela discricionariedade do julgador. Em seguida, falará da teoria de Ronald Dworkin, com ênfase no modelo de juiz e na interpretação em prol da integridade do direito.

Ato contínuo, terá vistas a proposta de argumentação pluralista em Robert Alexy, enaltecendo os elementos da ponderação. Por conseguinte, se debruçará sobre os postulados de Richard Posner e a hermenêutica dos fatos, com ênfase especial na visão do sistema jurídico como fonte de informações.

Por fim, fará uso da teoria de Jürgen Habermas para refletir sobre a questão da cidadania a lume de questões de direito processual penal. Tratará, também, com aporte em Ricardo Tinoco de Góes, de qual forma a democracia deliberativa-jurisdicional pode ser aplicada no ordenamento brasileiro nos casos de ausência de norma ou insuficiência da única norma existente.

\section{A SiSTEMÁtica dAs REgRAS DE RECONHECIMENTO E O PAPEL DA DISCRICIONARIEDADE EM H.L.A. HART}

Este estudo terá seu ponto de partida em H.L.A. Hart. A teoria deste autor pretende apontar o conceito de direito, suprindo a insuficiência deixada pela obra de John Austin, de modo que o primeiro teórico faz constantes diálogos com o segundo. (MORISSON, 2006, p. 423). É que Austin reduz o direito aos modais deônticos, sendo um modelo ainda baseado na filosofia de Hans Kelsen, na qual a únicas preocupação é com a dimensão formal do exercício da autoridade e consequente validade das normas. 
Em termos de evolução do pensamento jurídico, Hart forma o suprassumo do pensamento positivista (MORISSON, 2006, p. 417), encabeçando a corrente do chamado “neo-positivismo". (REALE, 2002, p. 330) Pensando no contexto histórico, apesar de não adentrar nos prolegômenos de uma digressão sobre imperativos morais ou conjecturas da filosofia política (MORISSON, 2006, p. 419), a teoria de Hart está situada em um período no qual a literatura social repensou o papel da instituições sociais - e dentre elas o direito - para "concretização dos desejos humanos" e desenvolvido da "boa sociedade" (MORISSON, 2006, p. 420).

Na conversa com o pensamento de Austin, Hart refuta a ideia de que o direito se sustente pela sua própria coercibilidade: é necessário ir além da violência das normas jurídicas, substituindo o medo das sanções por uma sistemática de regras sobrepostas. (MORISSON, 2006, p. 418). Por isso que diante das sociedades complexas, Hart diz que o exortamento de comandos não é o "modo-padrão" que o direito assume, sendo esta uma das diversas facetas que podem ser vistas no espectro jurídico. (HART, 2001, p. 26)

Daí que a produção legislativa se projeta para além da simples determinação de ordens as pessoas. (HART, 2001, p. 27) O imperativo das normas sancionadoras é factível quando se observam as produções do direito penal, contudo, não significa que o direito se reduza a mera estrutura de ordens legais. (HART, 2001, p. 29). Por isso, o direito para Hart está imbricado em uma estrutura que substitui a sanção pela aceitação comum das regras jurídicas. (MORISSON, 2006, p. 418)

Hart tem ciência de que na modernidade nenhum sistema jurídico sobrevive somente com normas primárias que ditem obrigações, faculdades, proibições, enfim, orientações comportamentais. Existe uma complexidade nas interações sociais que fazem ser necessárias normas secundárias, que tragam uma métrica para a concretização das primárias com parâmetros de aplicação, estruturação e em última análise, de legitimidade.

Estruturamente, Hart dirá que o direito é um sistema de regras primárias e secundárias. As regras primárias são os modais deônticos, enquanto as secundárias ofertam um paradgima para aplicação das primeiras, determinado como o direito pode ser modificado e as ações humanas concretizadas. (HART, 2001, p. 91).

Hart trará uma norma secundária última, semelhante a norma hipotética de Kelsen, denominada de norma de reconhecimento, sendo a verdadeira norma do sistema, pois é dela que convergem as normas secundárias sujeitas à aceitabilidade por aqueles que compõem a sociedade de livres e iguais. (HART, 2001, p. 111 - 113). 
Ora, essa regra última dará fundamento a todo o sistema jurídico, detendo supremacia perante as demais. (HART, 2001, p. 117) Logo, a dimensão interna do sistema jurídico é composta pelas normas primárias e secundárias, enquanto a externa é a norma secundária última. Isto leva a ser a pirâmide hartiana ser inversa quando comparado à de Kelsen.

O direito para Hart tem uma textura aberta e no campo da jurisdição. Trata-se de uma aplicação da filosofia da linguagem de Wittgenstein. (MORRISON, 2006. p. 436). Isto significa que nos casos de lacuna, o juiz irá preencher as lacunas através de um poder discricionário, criando o direito em face do caso concreto. (HART, 2001, p. 335)

Não obstante, a principal herança de Hart é a preocupação com a aceitabilidade do direito pelos destinatários, dando um contorno diferente a legitimidade, ainda que a norma de reconhecimento seja insuficiente para abarcar as questões morais e as necessidades normativas da sociedade. Ainda que a teoria de Hart tenha uma impregnação de conteúdos morais e valores que estejam a serviço do direito, isto não implica que o direito esteja subordinado a moral.

A correção do direito por uma ordem moral virá com a superação do modelo hartiano, pelo pós-positivismo, como se verá no próximo item.

\section{O MÉTODO HÉRCULES E O ROMANCE EM CADEIA DE RONALD DWORKIN}

Ronald Dworkin trabalha com uma relação circular para direito e moral: o direito está no campo da moral política, tem por antecedente a ética da moral pessoal, possui forma interpretativa e serve de nascedouro para o direito político, bastião da produção legislativa. (DWORKIN, 2014, p. 620 - 623) Assim, o referido autor Dworkin opta por uma leitura moral do direito que faz gênese aos princípios, verdadeiros trunfos políticos que os indivíduos detém para salvaguardar a sua liberdade contra eventuais abusos. (DWORKIN, 2002, p. XV)

Não obstante, próprio Dworkin deixa claro que seu pensamento faz contraponto com as elucubrações hartianas, dado que as regras jurídicas não correspondem a fonte primária do direito. (DWORKIN, 2002, p. 34 - 36). Daí que Dworkin parte da premissa que a decisão judicial deve manter a segurança jurídica, razão pela qual pretende mitigar a discricionariedade que se faz presente na teoria de Hart quando o julgador se depara com casos em que a solução não é contemplada pelo sistema jurídico.

O conteúdo moral do direito advém do processo legislativo que e da própria Constituição, esta última encarada como repositório princípiologico-normativo. É uma visão 
política da Constituição que abre o processo interpretativo das clausulas abstratas, de vasto conteúdo moral e de onde vão partir os subsídios para resolver as situações mais difíceis que a jurisdição é capaz de se deparar.

Em outras palavras, Dworkin dirá que existem regras, princípios e políticas. As regras contém a solução para situações jurídicas. Já os princípios são padrões observáveis que traduzem uma exigência moral, enquanto as políticas são os objetivos a serem alcançados pela comunidade. As regras são utilizadas para responder os casos fáceis, enquanto os princípios devem solucionar os casos difíceis. (DWORKIN, 2002, p. 36)

Enquanto componentes do sistema jurídico, os princípios tem o condão de complementar as eventuais lacunas existentes quando não existe uma norma aplicável ou quando a norma existente é insuficiente. Cada princípio aplicável terá um peso atribuível, baseado na importância e capacidade de resolver a controvérsia jurídica. (DWORKIN, 2002, p. 42)

Logo, a atividade interpretativa irá depender do caso concreto, ficando a argumentação desempenhada pelo julgador ao tipo de questão a qual está a julgar. Na ocasião de um hard case a decisão judicial detém um caráter político, trazendo a rebote os princípios como fundamento e a política como finalidade. (DWORKIN, 2002, p. 138 - 139) Ademais, cabe ao argumento utilizado demonstrar quais os direitos estão sendo respeitados ou garantidos. (DWORKIN, 2002, p. 129)

A ordenação hermenêutica de Dworkin é alicerçada em dois elementos: o romance em cadeia e o método Hércules. $\mathrm{O}$ romance em cadeia descreve a maneira que as decisões são produzidas, utilizando uma comparação com a atividade literária, já o método Hércules designa a forma que a argumentação jurídica será desempenhada pelo julgador.

A ilustração literária se prestará a salvaguardar a integridade do sistema jurídico e dirá que os precedentes judiciais operam na forma de uma corrente, na qual cada capítulo a ser escrito estará dando segmento ao anterior. O direito estará sempre reportando-se ao passado como paradigma para dirimir a questão do presente e essa mesma decisão irá projetar o futuro.

Desta feita, o juiz tem o dever interpretativo perante a própria história do direito, fazendo um verdadeiro processo de reconstrução do direito vigente. (DWORKIN, 2001, p. 238). Por seu turno, o método Hércules remete a um modelo de juiz que observa o conteúdo que a interpretação deve ter: o juiz Hércules deverá aplicar os princípios ao fixar os direitos do caso concreto, considerando as tradições morais da comunidade que estão presentes no registro institucional. (DWORKIN, 2001, p. 196). 
A principal crítica que pode ser feita a Dworkin recai no solipsismo do juiz Hércules, abrindo margem para questionar de que maneira fica a representatividade do cidadão. De fato, a proposta dworkiana satisfaz a integridade e a coerência do sistema jurídico e consegue aporte na interpretação reconstrutiva para satisfazer a legitimidade formal do decisório.

Contudo, fica a indagação: como Hércules pode completar toda a gama de interpretações que se manifestam em uma sociedade pluralista? Como fica o esforço cooperativo e discurso daqueles que por ventura serão destinatários da norma jurídica? Parece que a questão só encontrará resposta em uma teoria da argumentação jurídica pluralista, como a de Robert Alexy, objeto da próxima seção.

\section{ROBERT ALEXY E A TEORIA DA ARGUMENTAÇÃO JURÍDICA PLURALISTA BASEADA NA PONDERAÇÃO}

Robert Alexy tem filia pós-positivista, assim como Ronald Dworkin. Sua proposta recai na utilização de princípios e de uma aproximação necessária entre direito e moral. $\mathrm{O}$ enfoque de Alexy é denominado de constitucionalismo discursivo, consoante interligar os conceitos de direitos fundamentais, ponderação, discurso, jurisdição e representação. (ALEXY, 2012, p. 155)

Sua teoria tem início com a abertura de duas perspectivas sobre as quais o fenômeno jurídico pode ser observado e conceituado: a do participante e a do observador. Perspectiva do participante é aquela assumida por aquele que comparte da argumentação jurídica, tendo como membros o juiz que irá decidir, os advogados, juristas e cidadãos interessados. De outro orbe, a perspectiva do observador incide sobre a maneira que a decisão será feita. (ALEXY, 2011, p. 30)

É a perspectiva do participante trata do direito enquanto sistema normativo que tem uma pretensão de correção moral, composto de normas que não sejam extremamente injustas, dotadas de eficácia social plena ou possível e que junto aos princípios, dão apoio ao procedimento de aplicação do direito. (ALEXY, 2011, p. 151)

Igual com Dworkin, Alexy também se vale da distinção entre regras e princípios, tratando-a como elemento fundamental da dogmática do direito, servindo de ferramenta para esclarecimento de competências, a aplicabilidade dos direitos de liberdade e igualdade. (ALEXY, 2008, p. 87) 
A diferença fulcral reside na abertura das espécies normativas e sua operacionalização em face do caso concreto. As regras são rígidas e imediatamente aplicáveis, enquanto os princípios são abertos e abstratos, sendo necessário o exercício da ponderação, enquanto técnica interpretativa, para incidência destes no caso concreto. (ALEXY, 2012, p. 106)

Os direitos fundamentais podem possuir ambas características: como regras, servindo de proteção ao cidadão contra os arbítrios estatais e como um valor jurídico que irá orientar a produção normativa, face o seu efeito de irradiação. (ALEXY, 2012, p. 108 - 110) Daí o comportamento dos princípios como mandados de otimização, pois determinam que o bem jurídico tutelado seja realizado na maior quantidade possível em face das circunstâncias concretas. (ALEXY, 2012, p. 110)

De acordo com a Alexy, a ponderação enquanto tem como estrutura o princípio da proporcionalidade alicerçado nos subprincípios da idoneidade, da necessidade e da proporcionalidade em sentido estrito. (ALEXY, 2012, p. 110 - 111). Os três subprincípios irão pautar as etapas para realização da ponderação pelo órgão julgador e que irá proporcionar a racionalidade e legitimidade necessárias ao decisório.

O princípio da idoneidade trata do meio a ser utilizado, devendo ser aquele que não acarrete prejuízos universais, conquanto o princípio da necessidade determina que a ponderação só pode ser feita quando não for possível outra maneira de resolver a colisão. Sendo necessária a ponderação, esta será realizada nos ditames da proporcionalidade em sentido estrito, evitando que um princípio não mitigue o outro, devendo o vencedor prevalecer na exata medida necessária ao perdedor. (ALEXY, 2012, p. 110 - 111)

Na perspectiva alexista, há uma preocupação com a legitimidade que já desponta desde o conceito de perspectiva do participante: o autor se preocupa com a reconciliação da jurisdição constitucional com a democracia, fazendo inserir o elemento da representatividade no discurso jurídico, a qual é realizada argumentativamente. (ALEXY, 2012, p. 163)

Logo, a argumentação feita pelo juiz, por melhor que seja, não suplementa o argumento do cidadão. Para que os fundamentos da decisão sejam aceitáveis, deve haver simetria entre a argumentação do tribunal e aquela desempenhada pelo povo. É por intermédio da representatividade argumentativa que a teoria de Alexy tem um viés pluralista, já que permite que uma ampla gama de argumentações adentre nas eclusas da corte constitucional. (ALEXY, 2012, p. 165)

A falha que pode ser reportada à teoria de Robert Alexy é que a abertura ao pluralismo é tamanha que fica impossível obter uma argumentação razoável, o que fere de morte a 
segurança jurídica. Não obstante, a interpretação valorativa não pode estar condicionada ou amarrada à opinião pública.

O canal comunicativo deve permanecer aberto para que a legitimidade seja verdadeira, mas o próprio argumento levantando pelos cidadãos pode ser vencido argumentativamente no debate jurídico. Assim, a necessidade de ter critérios que permitem balizar a atividade do intérprete em face dos argumentos apresentados pela sociedade, como se estudará na teoria de Richard Posner, pensamento a ser investigado em seguida.

\section{O PRAGMATISMO JURÍDICO DE RICHARD POSNER E A HERMENÊUTICA PELOS FATOS}

Para Richard Posner, o termo pragmatismo comporta uma acepção especial: não se trata de conceitos ou generalizações, para o autor importa saber de fatos e consequências. É esta a tônica de sua proposta de jurisdição: que as decisões sejam baseadas em fatos jurídicos e extrajurídicos e prevejam a consequência que seus efeitos terão na realidade concreta. (POSNER, 2012, p. $357-358$ )

A despeito das diferenças conceituais, Posner vê uma aproximação entre o direito e a filosofia pragmática, consoante o pragmatismo possibilitar que as mentes dos juristas se abram a partir da dúvida, dos questionamentos céticos e das investigações que colocam em análise os fundamentos do sistema jurídico. (POSNER, 2012, p. 358 - 359). O autor se vale da experiência com o direito administrativo norte-americano para mudar a guinada proporcionada pelas experiências empíricas, aprimorando o estudo e a produção do direito positivo. (POSNER, 2012, p. 368 - 370)

No esteio de uma atividade jurídica pragmática, a interpretação deverá ficar atenta aos melhores resultados que podem ser produzidos pelo juiz, sem se desacoplar dos princípios constitucionalidade e da historiedade. Entretanto, o julgador pragmático se preocupa com a coerência dos precedentes quando a decisão baseada nestes for a melhor atenda as necessidades do presente e construa o futuro. (POSNER, 2012, p. 380-382)

Para o juiz pragmatista tem na legislação, na jurisprudência e no texto constitucional valiosas fonte de informações que restringem parcialmente sua discricionariedade para valoração fática dentro do processo. (POSNER, 2012, p. 382) Já os fatores externos ao direito, como argumentos econômicos, sociais, tudo aquilo que é manifestado por peritos e outros dados empíricos se mostra como uma informação extrajurídica. Na verdade, o pragmatista 
parte dos fatos para só então buscar o direito, em processo inverso ao da subsunção. (POSNER, 2012, p. 391).

Outra coisa que Posner chama atenção é que o juiz só deve decidir aquilo que já existe algum consenso social, sob pena da opinião pública invalidar o julgamento ao rejeita-lo. Ou seja, dois são os condicionantes da atividade interpretativa: elementos extrajurídicos e receptividade do público. (POSNER, 2012, p. 396). A tese de Posner é especialmente aplicável aos hard-cases dworkianos, nos quais existe uma lacuna dentro do sistema a ser suprida. Afinal, o magistrado não pode se abster de julgar os casos que lhe são apresentados. (POSNER, 2012, p. 409).

Diferentemente de Alexy, Posner cria balizas que permitem filtrar as argumentações: primeiro são consideradas aquelas relevante para o caso em espeque, segundo que elas passarão pelo contato com todo o arcabouço do sistema jurídico, que determinará a validade de uma norma.

O problema desta teoria, assim como a de Dworkin, é confiar ao julgador toda o protagonismo da atividade judicante, fechando-se ao que a opinião pública tem a dizer: ainda que Posner pense na aceitabilidade do julgado, não há previsão de participação cidadã na produção do julgado, razão pela qual a teoria ainda não se alinha plenamente a uma proposta verdadeiramente democrática da jurisdição.

Pelo que foi visto até o momento, é necessário que os princípios sejam considerados na atividade argumentativa, que deverá absorver os argumentos plurais e confrontar os mais relevantes com o que o texto constitucional diz. Todavia, a decisão democrática só existirá se for incrementado elementos de abertura procedimental no discurso jurídico, proposta esta levantada por Jürgen Habermas, autor a ser destrinchado logo abaixo.

\section{JÜRGEN HABERMAS E O DISCURSO JURÍDICO PROCEDIMENTAL}

Jürgen Habermas traz um modelo de jurisdição que pretende estabilizar o conflito entre a pretensão de tomar uma decisão correta e a segurança jurídica com base em um modelo procedimental. Propõe o autor que a judicatura deve de um só arremate satisfazer uma aceitabilidade racional argumentativa para proferir uma decisão consistente. (HABERMAS, 1997, p. 245 - 247)

Por isso o autor opta por uma nova via para além daquelas propostas pelas correntes da hermenêutica jurídica, realismo e positivismo jurídico. Habermas entende que as três são 
insuficientes: o positivismo tem preocupação exacerbada com a segurança jurídica, abrindo mão da aceitabilidade da decisão, pois fecha qualquer oportunidade de participação cidadã no processo judicial. (HABERMAS, 1997, p. 246)

O realismo, por seu turno, pode levar a um decisionismo que rasga a segurança jurídica por completo, transformando a jurisdição em verdadeiro utilitarismo irracional. (HABERMAS, 1997, p. 248 - 250). Já a corrente hermenêutica repensa a interpretação considerando a tradição jurídica e as pré-compreensões valorativas do interprete. (HABERMAS, 1997, p. 246 - 248)

Já o grande problema da hermenêutica é o solipsismo que decorre da atividade judicante: o juiz finda se apropriando da história institucional ao invés de debater com os outros atores processuais. (HABERMAS, 1997, p. 252) Ainda, destaca Habermas que o positivismo é incapaz de solucionar os hard-cases. (HABERMAS, 1997, p. 251)

Para basear sua própria teoria procedimental, Habermas adapta parte da teoria de Dworkin, fazendo um ajuste do caráter monológico de Hércules para o agir comunicativo, fazendo uma abertura para o núcleo procedimental da atividade argumentativa, possibilitando o discurso com os afetados pela decisão. (HABERMAS, 1997, p. 277)

Com este pensamento, Habermas sana a problemática do solipsismo, consoante a decisão se transformar em um construto baseado no esforço cooperativo que envolve todos os participantes da comunicação pública, que hão de guiar comunicativamente o juiz na précompreensão paradigmática do direito. (HABERMAS, 1997, p. 278)

Na reconstrução prática da interpretação, Habermas oferta para Hércules uma teoria de argumentação jurídica que forma a aceitabilidade da decisão, fazendo com que seja vitorioso o argumento racional. (HABERMAS, 1997, p. 280 - 282)

De outra banda, Habermas também irá blindar Hércules das críticas argumentativas, propondo que a construção decisória do julgador é provisória e submetida aos argumentos e informações disponíveis sobre o tema que estiver em julgamento: a decisão correta deverá ser construída através de uma busca cooperativa pela verdade. (HABERMAS, 1997, p. 283)

Isto implica em reconhecer que o discurso jurídico não é auto-suficiente, de modo que uma formação imparcial do juízo requer o preenchimento das condições comunicativas, respaldadas na abertura argumentativa para tudo aquilo que possa influenciar na decisão. (HABERMAS, 1997, p. 287). Insta salientar que para Habermas, o discurso jurídico é independente da moral e da política, a despeito de admitir argumentos extralegais, desde que devidamente transcritos para o código jurídico. (HABERMAS, 1997, p. 257) 
Será através da apreciação destes elementos que a decisão pode ser objeto de recurso, naquilo Habermas chama de auto-reflexão institucional, na qual as instancias superiores uniformizam a aplicação do direito e mantém a jurisprudência íntegra. (HABERMAS, 1997, p. 294 - 295). Em seguida, será falado sobre a aplicação do modelo habermasiano na jurisdição brasileira, tanto no prisma da aplicação direta nas jurisdições constitucional e ordinária.

\section{A PROPOSTA DE RICARDO TINOCO DE GÓES DE LEGITIMIDADE PARA ALÉM DE JÜRGEN HABERMAS}

Ricardo Tinoco de Góes utiliza um aporte conjunto em Robert Alexy, Ronald Dworkin, Willis Santiago Guerra Filho, Klaus Günther, Rudolf Weithölter e Hans-Georg Gadamer para fazer aplicar o modelo discursivo habermasiano para a jurisdição brasileira. Para uma melhor definição do papel da jurisdição nos moldes estabelecidos por Habermas e aplicada por Tinoco é plausível falar das situações para os casos concretos de aplicação da norma nas seguintes situações: A primeira é em caso de anomia e a segunda é a da insuficiência da única norma existente (GÓES, 2013, p. 144).

Utilizando-se do "recurso do paradigma direto", após análise fática completa do caso o Juízo fará uma adequação para aplicação da melhor norma dentre as possíveis existentes no ordenamento e que melhor se adequem ao caso. Para isso é necessário haver uma minuciosa descrição das circunstâncias do caso, o que Habermas define como "uma descrição exaustiva dos fatos relevantes para a interpretação da situação em um caso controverso" (GÓES, 2013, p. 145).

Quando há muitos regramentos para a melhor escolha não implica em um problema nem em uma tarefa difícil ao intérprete, mas sim quando não há qualquer norma aplicável ao caso. Nessas situações o jurista deve procurar a resposta na "realidade jurídica de sua comunidade". Nesse instante é possível observar a relação entre a teoria habermasiana e o pragmatismo, haja vista o enlace existente na complementariedade para adequação (lógica pragmática) (GÓES, 2013, p. 146-147).

A argumentação para a escolha de uma ou da outra norma "que mais se aproximar da variedade de sentidos exteriorizada pelo caso", já que o Tribunal não pode se esquivar da jurisdição. (GÓES, 2013, p. 147). O autor chama atenção para a escolha de uma norma feita sem se levar em conta o procedimento discursivo e democrático, ventilando a possibilidade 
de, nesses casos, a sociedade estar diante de situações "reconhecidamente antidemocráticas em matéria de aplicação de direito", haja vista a necessária deliberação e discussão por parte das esferas públicas no tocante à validade. (GÓES, 2013, p. 148)

Imprescindível lembrar o cerne da teoria habermasiana da deliberação democrática residente na formação de opinião pública realizada de forma ampla, participativa e voluntária por todos os cidadãos interessados. Após o câmbio dessas informações com as instituições aí haverá a materialização dessa vontade de forma institucionalizada, por meio do chamado fluxo de comunicação, ou seja, o que Habermas chamou de "tentativa de vencer a tesão entre a facticidade e a validade do direito pela via democrática. (GÓES, 2013, p. 149-150).

Aspecto interessante reside no que Habermas chamou de zonas cinzentas ou chamados “casos difíceis” para os quais é necessário se lançar mão do recurso principiológico para solucionar uma situação para a qual a legislação é insuficiente, devendo haver, também, uma preocupação em bem fundamentar o direito realizado no âmbito do discurso de aplicação, devendo essa interpretação e fundamentação ocorrerem no âmbito do debate público. (GÓES, 2013, p. 151-152)

Ainda é necessário observar o chamado déficit de legitimidade que permeia o judiciário brasileiro como um todo no sentido de não haver uma interpretação construtiva da Constituição, principalmente no tocante aos conflitos atuais para os quais é necessário um esforço maior dos juristas para uma atividade argumentativa maior "inerente ao discurso e capaz de absorver toda a influência da esfera pública" para captação da realidade e posterior aplicação do direito. (GÓES, 2013, p. 156-157)

Partindo-se do pressuposto da impossibilidade da jurisdição modificar as construções legislativas, o contrário pode se verificar, podendo, inclusive, o legislador, rever decisões e omitir suas próprias lacunas e contradições em razão da constante evolução social ocorrida na contemporaneidade. Vista sob o prisma da interpretação conforme, a técnica da argumentação jurídica perfeitamente se amolda à referida interpretação contemplando a esfera pública. (GÓES, 2013, p. 237-238)

Nesse sentido é possível concluir pela aceitação do discurso de aplicação normativa norteada pelo princípio guia da interpretação de qualquer dispositivo conforme a Constituição, haja vista a possibilidade de haver um choque principiológico o qual ensejará uma discussão deliberativa quanto ao conflito perpetrado e qual princípio deverá ser priorizado ou invocado no caso. (GÓES, 2013, p. 239-240)

As decisões tomadas no âmbito do Tribunal Superior chamam atenção para a solução controversa quanto à declaração de inconstitucionalidade por omissão não alcançar situações 
já tratadas pela lei inconstitucional. Para a teoria de Habermas, seria interessante restabelecer a situação anterior e garantir efeitos ex-tunc em razão desse posicionamento propiciar o debate social a fim de promover convergência entre o texto constitucional e a vontade social. (GÓES, 2013, p. 241-242)

Ora, se a lei é omissa não há solução clara para o caso ou haverá para o caso uma norma aplicável, porém inadequada e, consequentemente, inconveniente. Deverá, portanto, haver o debate entre a esfera pública e a jurisdição com a finalidade de uma interpretação reconstrutiva ou uma pronúncia de nulidade, ambas pautadas na argumentação, nos valores e na legitimidade. (GÓES, 2013, p. 243)

No caso das omissões absolutas do legislador, momento em que o Judiciário deverá apresentar regra de decisão, também propicia o debate amplo por meio da interlocução das instituições com a esfera pública, ou seja, jurisdição e parlamento possuem as mesmas obrigatoriedades e a mesma necessidade de garantir validação às suas normas por meio da argumentação interlocutória entre os setores da esfera pública e das instituições estatais. (GÓES, 2013, p.246)

Mais uma vez a complexidade das sociedades modernas enseja uma forma cada vez mais rebuscada de julgar no sentido de garantir mais legitimidade e retratar a vontade real social. Prova disso reside na questão da tutela dos interesses difusos. Instrumento pelo qual se faz necessária a discussão profunda entre o espaço público e o órgão decisor. É preciso haver abertura para tratar da temática dos interesses difusos, estes cada vez mais presentes na sociedade contemporânea e a maior prova do desenvolvimento da forma de se fazer jurisdição, pois é o tipo de ação que enseja debate reflexivo e profundo em razão de versar sobre interesses da coletividade.

Nesse caso, a ação coletiva é vista como um mero instrumento de participação e sim como "meio efetivo e real para uma democracia deliberativa participativa e cidadã". (GÓES, 2013, p. 248) Na mesma linha se dá o instituto do amicus curiae, devendo garantir participação ativa na tarefa cidadã de promover o diálogo de forma compartilhada com a jurisdição e a esfera púbica.

O canal aberto de argumentação e interlocução entre instituição e esfera pública propicia regra de decisão mais favorável nos moldes sociais almejados, pois ninguém melhor que a sociedade para conhecer seus problemas e fornecer soluções. Para o caso das ações coletivas, civis públicas e populares o canal de abertura comunicativa interlocutório entre as partes interessadas possibilita uma melhor atuação do Poder Judiciário de forma fundamentada e legítima (GÓES, 2013, p. 249). 


\section{CONCLUSÃO}

No afã de encontrar uma teoria de decisão democracia, o presente artigo percorreu uma série de autores, elencando quais os postulados adotam e quais críticas podem ser apontadas. Findou por radicar sua base em uma teoria de decisão alinhada com a democracia deliberativa, na forma preconizada por um pós-positivismo procedimental.

Por tal razão, as teorias de H.L.A. Hart, Ronald Dworkin, Robert Alexy e Richard Posner se mostram insuficientes para suprir a demanda por uma jurisdição verdadeiramente democrática, que corresponda aos anseios de uma cidadania pluralista. Daí este estudo ter optado pelo método diálogo e firmado uma posição notadamente habermasiana, identificando as particularidades da teoria de Jürgen Habermas e tecendo duas considerações sobre sua aplicabilidade no ordenamento jurídico brasileiro.

Somente desta maneira é que a vontade legítima será exercida: cidadãos politicamente autônomos, livre de imposições arbitrárias, em que o Direito será nutrido pela solidariedade que surge a partir do efetivo exercício da palavra 'cidadão' através do agir comunicativo. Não obstante, este estudo foi impregnado por uma intenção normativista, estando a pesquisa na perspectiva de um dever-ser, ainda que no item que diz respeito ao processo penal tangencie os limites de uma análise representativa.

Por fim, na prática da autodeterminação, onde o cidadão exercerá suas liberdades comunicativas, o direito se achará, em última instância, como consultor de dissensos, não apenas para analisar do topo, numa relação triangular entre juiz, autor e réu, livre de influências relacionais, assumindo a ingênua figura de juiz neutro, mas para integrar coletivamente como parte de uma nova história, capaz de fazer surgir uma solução boa para todos, onde a figura do perdedor seria eternamente banida.

Em face de todo o exposto, a pesquisa encerra objetivando servir de base para indagações futuras, as quais podem recair sobre de que maneira a jurisdição procedimental pode ser realizada no âmbito do Código de Processo Civil ou até mesmo na legislação de Processo Penal, consoante ser a proposta de jurisdição democrática aquela que verdadeiramente transparece o acesso à justiça como um direito fundamental do cidadão. 


\section{REFERÊNCIAS}

Constitucionalismo discursivo. Trad. Luís Afonso Heck. 4. ed. Porto Alegre: Livraria do Advogado, 2012

_ Levando os direitos a sério. Trad. de Nelson Boeira. São Paulo: Martins Fontes, 2002 2001

Uma questão de princípio. Trad. de Luís Carlos Borges. São Paulo: Martins Fontes,

Teoria dos direitos fundamentais. Trad. Virgílio Afonso da Silva. São Paulo: Malheiros, 2008

ALEXY, Robert. Conceito e validade do direito. Trad. Gercélia Batista de Oliveira Mendes. São Paulo: WMF Martins Fontes, 2011

DWORKIN, Ronald. A raposa e o porco espinho: justiça e valor. Trad. de Marcelo Brandão Cipolla. São Paulo: WMF Martins Fontes, 2014

GÓES, Ricardo Tinoco de. Democracia deliberativa e jurisdição: a legitimidade da decisão judicial a partir e para além de J. Habermas. Curitiba: Juruá, 2013

HABERMAS, Jürgen. Direito e democracia: entre facticidade e validade. Volume I. Trad. de Flávio Beno Siebeneichler. Rio de Janeiro: Tempo Brasileiro, 1997

HART, Herbert Lionel Adolphus. O conceito de direito. 3. ed. Trad. A. Ribeiro Mendes. Lisboa: Fundação Calouste Gulbenkian, 2001

MORISSON, Wayne. Filosofia do direito: dos gregos ao pós-modernismo. Trad. Jefferson Luiz Camargo. São Paulo: Martins Fontes, 2006

POSNER, Richard Allen. A problemática de teoria moral e jurídica. Trad. Marcelo Brandão Cipolla. São Paulo: WMF Martins Fontes, 2012

REALE, Miguel. Filosofia do direito. 19. ed. São Paulo: Saraiva, 2002 
JURISDICTION JUSPHILOSOPHICAL LININGS: FROM THE POSITIVISM INTO THE PROCEDURAL POST-POSITIVISM

\begin{abstract}
This articles aims to study a judicial decision model able to answers the citizenship interests. It utilizes both the dialectical method and the deductive method, with qualitative and normative research based on doctrinal sources, with emphasis on law philosophy and constitutional right theories. It understands that the Hart's positivism, Dworkin and Alexy's post-positivism and Posner juridical pragmatism theories are insufficient to account for the decisions legitimacy. It finds in Habermas a jurisdiction procedural model able to unleash the democratical and cooperative dialogue between the jurisdictional actors. After that, it investigates the habermasian theory application in the ordinary jurisdiction with emphasis on the criminal procedural law and the constitutional jurisdiction backed by Ricardo Tinoco de Góes. In the end it suggest that the Habermas model be utilized for future researches about it's applicability in the brazilian law.
\end{abstract}

Keywords: Judicial decision legitimacy. Deliberative democracy. Procedural post-positivism. 